\title{
Dynamics of Underwater Bar of Sandy Coast under the Influence of Wave Action According to the Monitoring Observations
}

\author{
D. V. Korzinin*, M. N. Shtremel \\ Shirshov Institute of Oceanology, Russian Academy of Science, Moscow, Russian Federation \\ * korzinin2000@mail.ru
}

Purpose. Morphodynamic system of the accumulative sandy coast can include one or more underwater bars. Position and shape of the underwater bar can reflect both seasonal changes of the coastal profile and its unidirectional movements landward and seaward. Determination of the character of the underwater bar movement under the influence of various wave conditions permits to reveal common factors of the coastal deposit multidirectional transport along the coast profile.

Methods and Results. The results of field observations of morphodynamics of a section of the Baltic Spit sandy coast (600 m length) were analyzed. From May to November 2019, a series of measurements of the coastal zone relief were conducted. The obtained data were analyzed along with the wave regime parameters (reanalysis ERA5 data was used). The coastal profile of the area under study is complicated by the external underwater bar with its crest located at the depth $2.65 \mathrm{~m}$, and by the internal one of a crescent shape.

Conclusions. Analysis of displacement of the external underwater bar from May to November showed that this form was of a morphodynamics two-dimensional character, i.e. it possessed the same morphometric characteristics along the coast. It was revealed that the underwater bar crest was located at the depths close to those of wave breaking during the most recent relatively strong and sustainable storm. Based on this concept as well as on the available literature data on the relationship between a wave height and dynamics of an underwater bar crest, described is the landward displacement (recorded during the observation period) of the external underwater bar. Due to the field data, it was shown that the underwater bar morphodynamics was effected both by duration of individual waves and by difference between the wave parameters of a sequence of storm events.

Keywords: sandy coast, coastal profile, wave regime, underwater bar, stages of storm.

Acknowledgements: the investigation was carried out within the framework of the state task of the Shirshov Institute of Oceanology, RAS (theme No. 0149-2019-0005) and financial support of RFBR (project No. 18-05-00741 and project No. 18-55-45026).

For citation: Korzinin, D.V. and Shtremel, M.N., 2020. Dynamics of Underwater Bar of Sandy Coast under the Influence of Wave Action According to the Monitoring Observations. Physical Oceanography, [e-journal] 27(4), pp. 390-401. doi:10.22449/1573-160X-2020-4-390-401

DOI: $10.22449 / 1573-160 X-2020-4-390-401$

(C) D. V. Korzinin, M. N. Shtremel, 2020

(C) Physical Oceanography, 2020

\section{Introduction}

Morphodynamic system of an accumulative sandy coast can include one or more underwater bars. The number of bars and the nature of their evolution are associated with the budget of coastal-marine sediments, the initial slopes of the bottom and the wave impact intensity. In [1, 2], the main types of non-tidal bars of the open sea coasts are presented, which include a two-dimensional alongshore bar (parallel to the coast), a three-dimensional bar (with a variability step along the coast of $10^{2}-10^{3} \mathrm{~m}$ ) and a bar adjoining the coast at relatively equal distances (crescent bar). Submarine bars of different types can coexist within the same morphodynamic system. An example of such a system is a combination of an external large submarine bar and smaller internal bars. In this system, both 
external and internal bars can have a crescent shape and adjoin the coast at equal distances.

Comprehensive studies of the behavior of coastal systems with two underwater bars, based on field data and mathematical modeling [3], have shown that the relationship between underwater bars of different orders increases with a higher inhomogeneity of the outer bar in depth. In this case, during relatively weak storms, the movement of sediments to the coast is facilitated, which is due to an increase in the role of horizontal circulation. A bar that is more straightened along the coast is more susceptible to displacement towards the sea and degradation as a result of the increased countercurrent effect. The studies on the shores of the Gulf of Lyons in the Mediterranean Sea $[4,5]$ have shown that the outer coastal bars with a decrease in the intensity of waves can degrade under effect of sediment wave transport towards the coast and under certain conditions can be conserved, i.e. are not affected by the wave impact.

Determination of the regularities of submarine bar morphodynamics is an urgent task of coastal science. The position and shape of a submarine bar can be an indicator of seasonal changes in the coastal profile [6-8] and thus determine possible deformations related to the seasonal wave cycles. At the same time, the determination of the submarine bar displacement regularities under effect of certain waves will provide more accurate description of the processes of coastalmarine sediment multidirectional transport along the coastal profile.

In order to solve these tasks, the observation results of submarine bar natural systems evolving under effect of storms of varying intensity and structure are of particular value. In this work, the data of field observations over the system of underwater bars carried out at a special research site are used as initial materials.

\section{The study area and initial data}

The research site "Baltiysk-2019" is located on the open sea coast of the Baltic Spit, at $3500 \mathrm{~m}$ distance from the strait connecting the Kaliningrad Bay with the Baltic Sea (Fig. 1). The research site includes the surface of the coastal zone to the surface adjacent to the coastal ledge and the underwater coastal slope down to $7-8 \mathrm{~m}$ depth.



F i g. 1. Location of the research site at the Baltic Spit (the southeastern part of the Baltic Sea) PHYSICAL OCEANOGRAPHY VOL. 27 ISS. 4 (2020) 
The coastal zone relief within the research site is represented by 30-35 m wide sandy beach with a coastal cliff in its rear part. The junction of the beach and the coastal scarp is covered by aeolian sand deposit (Fig. 2, a). The cliff is shallow, sodded above the aeolian sand deposit, and in some areas it has two tiers separated by a slightly sloping terrace-like surface. The upper edge of the cliff has a rounded shape and is implicitly expressed. The surface adjacent to the edge of the cliff is held together by trees and shrubs.
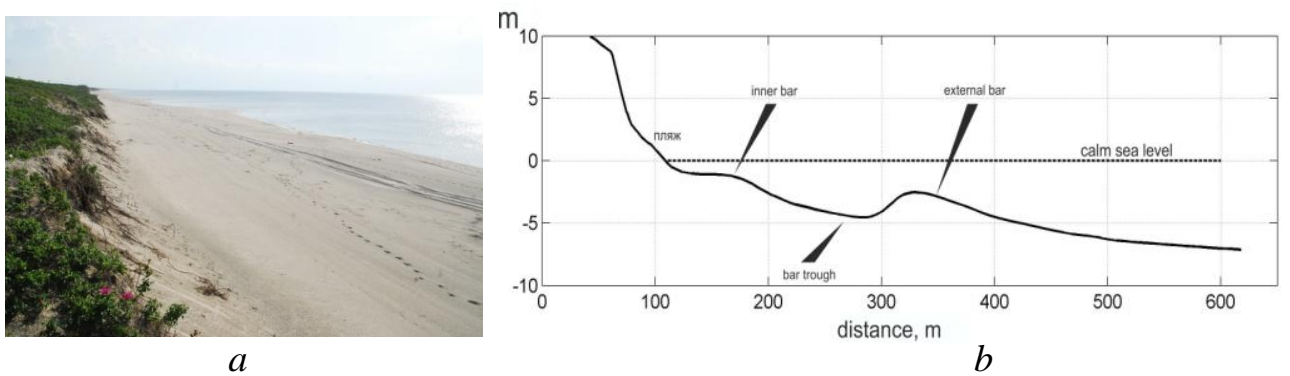

F i g. 2. Relief of the coastal zone above-water part at the research site "Baltiysk-2019" $-a$ and basic morphometric elements of the coastal profile $-b$

The beach is dissected from the outside by large cusps with 180-200 m step between their peaks. In the lower part of the underwater coastal slope a large submarine bar is located. The inner slope of the bar is steep (0.06 slope), the outer one is more gentle ( 0.027 slope). The top of the bar is located at a depth of about $2.6 \mathrm{~m}$, the depth on the bar inner side is $4.5 \mathrm{~m}$ (Fig. 2, $b$; morphometric parameters are given according to depth measurements performed in May 2019).

The measurements of the beach and surf zone topography were carried out at the research site using a ground-based GPS complex, and depth measurements were taken from a small vessel. In 2019, four series of measurements were performed (Table 1).

The source of wave data in our study is ERA5 reanalysis (https://cds.climate.copernicus.eu/cdsapp\#!/dataset/reanalysis-era5-single-levels?tab=form) of the European Center for Medium-Range Weather Forecasts (ECMWF). ERA5 reanalysis replaced ERA-Interim in 2019. The advantage of the new version of reanalysis lies in higher spatial and temporal resolution (spatial is $0.5^{\circ}$ and temporal is $1 \mathrm{~h}$ compared to $1^{\circ}$ and $6 \mathrm{~h}$ for ERA-Interim). Wave data in ERA5 were obtained using WAM spectral wave model described in [9]. Although the same wave model was used in ERA-Interim, the accuracy of wind calculation applied to the model as input data is $20 \%$ higher in ERA5 compared to ERA-Interim [10], as shown by comparing the significant wave height calculated in two versions of the model with the field data [11]. 
Basic stages of measurements of the coastal zone relief within the framework of studies at the research site "Baltiysk-2019"

\begin{tabular}{|c|c|c|c|}
\hline $\begin{array}{l}\text { Stage } \\
\text { number }\end{array}$ & Date & Type of work & $\begin{array}{c}\text { Hydrodynamic conditions } \\
\text { (during measurements wave } \\
\text { parameters were assessed } \\
\text { visually) }\end{array}$ \\
\hline 1 & $\begin{array}{l}\text { May 21-23, } \\
2019\end{array}$ & $\begin{array}{l}\text { Topographic survey of relief of } \\
\text { the above-water coastal zone. } \\
\text { Measurements of the underwater } \\
\text { coastal slope depths }\end{array}$ & Calm \\
\hline 2 & $\begin{array}{l}\text { July } 8-10 \\
2019\end{array}$ & $\begin{array}{l}\text { Topographic survey of relief of the } \\
\text { above-water coastal zone }\end{array}$ & $\begin{array}{c}\text { Average height of wind } \\
\text { waves } \\
0.5-0.8 \mathrm{~m}\end{array}$ \\
\hline 3 & $\begin{array}{l}\text { July } 30 \\
2019\end{array}$ & $\begin{array}{l}\text { Measurements of the underwater } \\
\text { coastal slope depths }\end{array}$ & Swell wave heights $0.3-0.4 \mathrm{~m}$ \\
\hline 4 & $\begin{array}{l}\text { November } \\
8-9,2019\end{array}$ & $\begin{array}{l}\text { Topographic survey of relief of the } \\
\text { above-water coastal zone. } \\
\text { Measurements of the underwater } \\
\text { coastal slope depths }\end{array}$ & Calm \\
\hline
\end{tabular}

The coordinates of the point closest to the research site are $55^{\circ} \mathrm{N}, 19.5^{\circ} \mathrm{E}$ $(50 \mathrm{~km}$ to the north-west of "Baltiysk-2019" research site, the depth at the computational point is about $80 \mathrm{~m}$, the shortest distance to the coast is $28 \mathrm{~km}$ ).

\section{Methods}

The study assumes that the top of the submarine bar corresponds to the wave breaking depth. This position was first noted in [12] based on a series of wave regime and coastal profile observations. Based on this assumption, the wave regime preceding the measurements of the bottom topography can be associated with the position of the submarine bar crest.

Wave breaking depth $d_{\mathrm{cr}}$ can be determined by the coefficient $\gamma_{\mathrm{cr}}$ :

$$
\gamma_{\mathrm{cr}}=H_{\mathrm{cr}} / d_{\mathrm{cr}}
$$

where $H_{\mathrm{cr}}$ is a height of breaking waves. The coefficient $\gamma_{\mathrm{cr}}$ has different values depending on the bottom slope of and the steepness of the waves. In [13] the following dependence was proposed:

$$
\gamma_{\mathrm{cr}}=1.14 \xi^{0.21}
$$

where $\xi$ is Irribaren number determined by the following ratio:

$$
\xi=\frac{s}{\sqrt{H_{\infty} / L_{\infty}}},
$$


here $H_{\infty}$ and $L_{\infty}$ are height and length of waves at the deep water; $s$ is a bottom slope ( 0.033 for the coast area under study). Wave length is determined by the ratio for the deep water

$$
L_{\infty}=\frac{g T m^{2}}{2 \pi},
$$

where $T m$ is an average wave period at the deep water. Wave height in the breaking point can be obtained from the correlation from [13]:

$$
\frac{H_{\mathrm{cr}}}{H_{\infty}}=0.53\left(\frac{H_{\infty}}{L_{\infty}}\right)^{-0.24} \text {. }
$$

A study of the bar response to the wave impact at Lake Huron [14] showed that the bar shifts towards the coast with the crest lowering when the following condition is satisfied:

$$
\frac{H_{\mathrm{rms}}}{h_{c}}<0.3,
$$

where $H_{\mathrm{rms}}$ is a root-mean-square wave height; $h_{c}$ is a depth above the crest. $H_{\text {rms }}$ value is related to the wave height $(H s)$ in accordance with the Rayleigh distribution [15] by the expression

$$
H_{\mathrm{rms}}=H s / \sqrt{2} .
$$

Thus, expression (6), with regard to dependence (7), takes the following form:

$$
\frac{H s}{h_{c}}<0.42 .
$$

When processing the results of observations over the bottom topography and data on wave modes, dependencies (1) - (5) are applied to determine the wave breaking depths during certain storm waves and to compare the obtained values with the measured position of the external submarine bar crest. Based on dependence (8), we make an assumption about the tendencies of the submarine bar displacement towards the coast with a decrease in the intensity of storm waves.

\section{Results}

Based on the comparison results of three surveys of underwater coastal slope relief (Table 1), a displacement of the accumulative protrusions of cusps in the south-western direction by $88 \mathrm{~m}$ for May - November period was revealed. The study of the dynamics relief was carried out on two profiles, each of which corresponds to the position of an individual cusp protrusion in May and November (Fig. 3). The morphodynamics of the underwater bar was analyzed according to the positions of the bar crest and the bar trough located closer to the coast. The analysis results are presented in Fig. 4 and Table 2. 


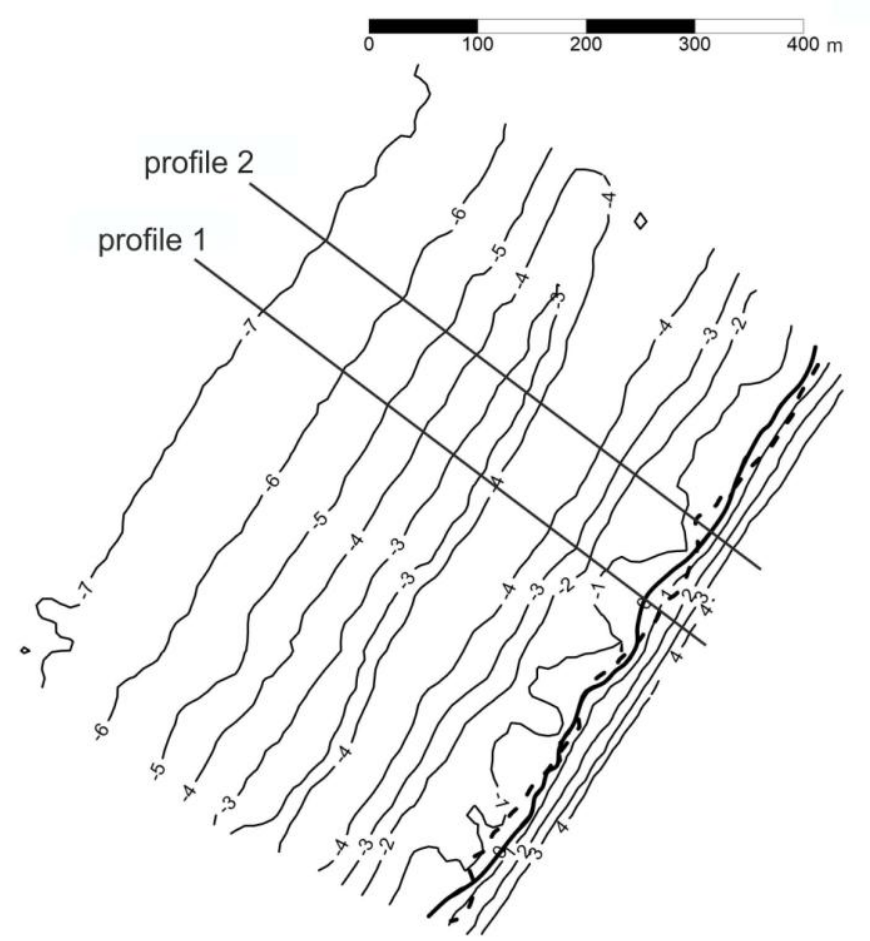

F i g. 3. Coastal zone relief from the 7-8 $\mathrm{m}$ depth to the beach rear measured in November, 2019. Bold lines show the water edge location in November (solid line) and in May (dotted line), 2019
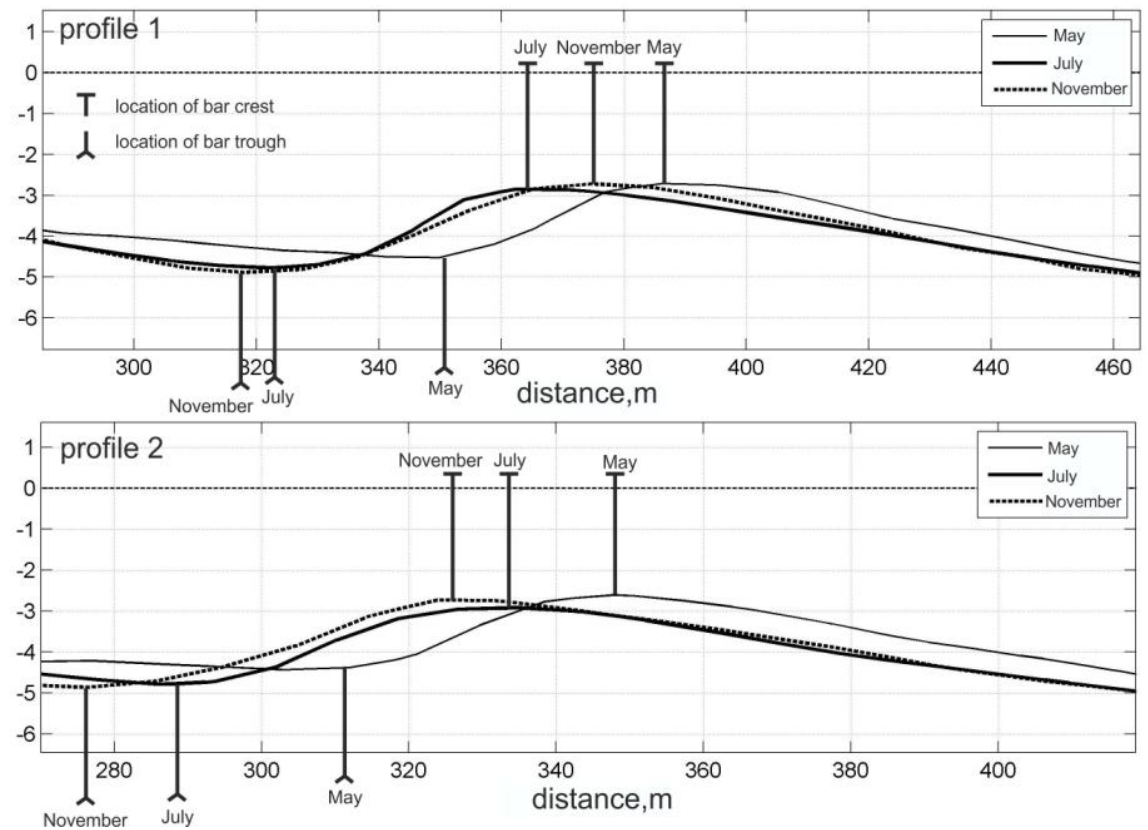

F i g. 4. Analysis of the external underwater bar morphodynamics using the profiles under consideration 


\section{Quantitative characteristics of the external underwater bar displacement on the profiles under consideration}

\begin{tabular}{c|c|c|c|c|c}
\hline \multirow{2}{*}{$\begin{array}{c}\text { Profile } \\
\text { number }\end{array}$} & \multirow{2}{*}{ Bar element } & $\begin{array}{c}\text { Distance, } \mathrm{m} \\
\text { (landward } \\
\text { direction) }\end{array}$ & $\begin{array}{c}\text { Depth } \\
\text { change, } \mathrm{m}\end{array}$ & $\begin{array}{c}\text { Distance, } \mathrm{m} \\
\text { (landward } \\
\text { direction) }\end{array}$ & $\begin{array}{c}\text { Depth change, } \\
\mathrm{m}\end{array}$ \\
\cline { 2 - 5 } & \multicolumn{2}{|c|}{ May- July } & \multicolumn{2}{|c}{ July- November } \\
\hline \multirow{2}{*}{1} & bar crest & 26 & -0.70 & $\mathbf{1 3}$ & 0.7 \\
\cline { 2 - 2 } 2 & bar trough & 17 & -0.24 & 4 & -0.1 \\
\cline { 2 - 2 } & bar crest & 14 & -0.30 & 10 & 0.2 \\
\cline { 2 - 3 } & bar trough & 18 & -0.35 & 10 & -0.1 \\
\hline
\end{tabular}

$\mathrm{N}$ o t e. The value implying seaward direction is marked out by thick print.

It was revealed that during the first study period under study (May - July) a noticeable displacement of the underwater bar towards the coast took place. During the second period (July - November), bar position changed insignificantly; moreover, during this period on profile 1 a displacement of the bar crest in the seaward direction was recorded, on profile 2 - in the landward one. During the entire period of measurements, the bar trough shifted towards the coast.

In general, the following trend has been recorded. During the first study period, the underwater bar shifts in the landward direction with the depth increase over the crest and trough. In the second period, the bar crest is relatively stable, but its height increases. The multidirectional displacements of the bar crest are insignificant, which shows that for the period under study the ridge has a twodimensional character of morphodynamics, i.e. without noticeable changes in the plan outlines.

During the storm on May 12-16, 2019 (Fig. 5), the wave height reached $1.9 \mathrm{~m}$. In the subsequent attenuation stage, its mean value was $1.4 \mathrm{~m}$. According to the performed calculations (Table 3 ), the wave breaking depth in the maximum phase was $3.39 \mathrm{~m}$, in the storm attenuation phase $-2.47 \mathrm{~m}$. Thus, on the eve of the first series of surveying works, the underwater bar was located at depths close to the wave breaking ones of the previous storm event.

According to the wave data, during the period from May to July one strong storm, at which a significant wave height $(H s)$ reached $4 \mathrm{~m}$ (see Fig. 5, June 20 - July 10 period), took place. The attenuation of this storm occurred in stages and contained three consecutive peaks with $H_{s}$ values equal to 2.9; 2 and $1.7 \mathrm{~m}$. 

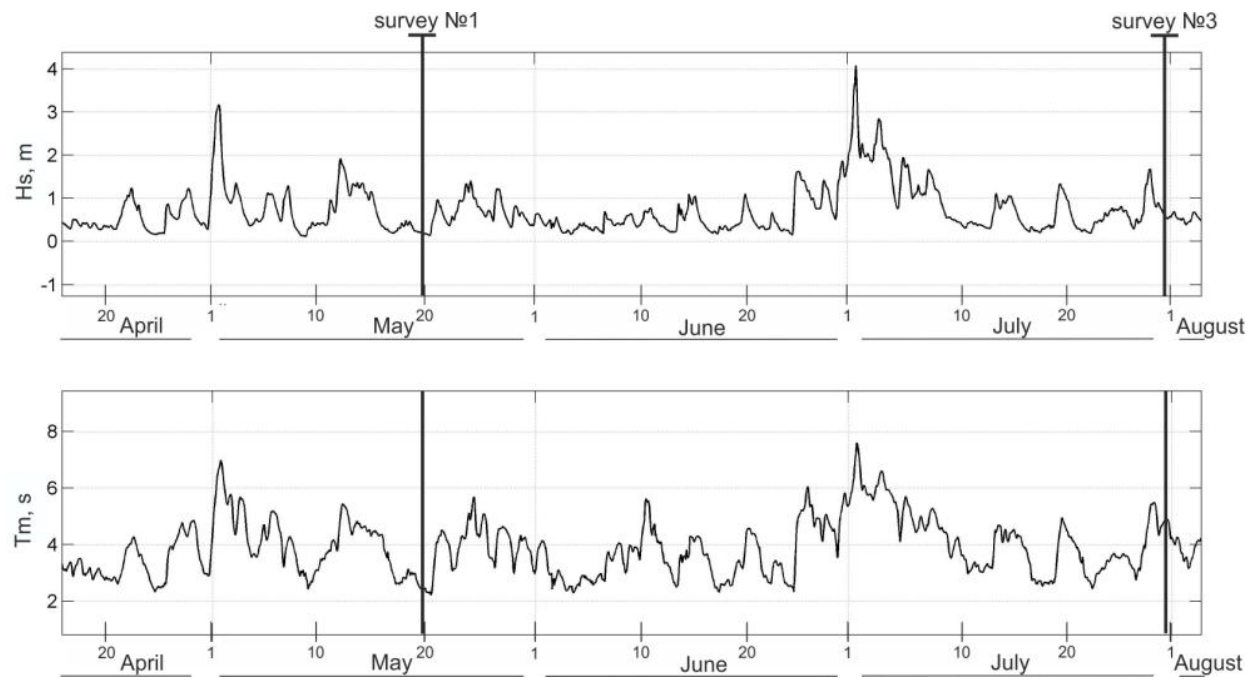

F i g. 5. Wave parameters (reanalysis ERA5) in May - July, 2019

Table 3

Intermediate variables and results of calculating the wave breaking depths $\left(d_{\mathrm{cr}}\right)$ during the storm on May, 11-16 preceding the relief measurements in course of stage 1 (see Table 1 and Fig. 5)

\begin{tabular}{l|c|c|c|c|c|c|c}
\hline Storm stage & $\begin{array}{r}H s, \mathrm{M} / \\
H s, \mathrm{~m}\end{array}$ & $T m, \mathrm{c}$ & $\begin{array}{c}L_{\infty}, \mathrm{M} / \\
L_{\infty}, \mathrm{m}\end{array}$ & $\begin{array}{c}H_{\mathrm{cr}}, \mathrm{M} / \\
H_{\mathrm{cr}}, \mathrm{m}\end{array}$ & $\xi$ & $\gamma_{\mathrm{cr}}$ & $d_{\mathrm{cr}}$ \\
\hline maximum phase & 1.9 & 5.5 & 47.21 & 2.18 & 0.065 & 0.642 & 3.39 \\
attenuation & 1.4 & 4.5 & 31.60 & 1.57 & 0.062 & 0.635 & 2.47 \\
\hline
\end{tabular}

Ta ble 4

Intermediate variables and results of calculating the wave breaking depths $\left(d_{\text {cr }}\right)$ during the storm in July, 13-16 and the subsequent ones preceding soundings in course of stage 3 (see Table 1 and Fig. 5)

\begin{tabular}{l|c|c|c|c|c|c|c}
\hline \multicolumn{1}{c|}{ Storm dates } & $H s, \mathrm{~m}$ & $T m, \mathrm{c}$ & $L_{\infty}, \mathrm{m}$ & $H_{\mathrm{cr}}, \mathrm{m}$ & $\xi$ & $\gamma_{\mathrm{cr}}$ & $d_{\mathrm{cr}}$ \\
\hline & 4.0 & 7.6 & 90.14 & 4.48 & 0.062 & 0.635 & 7.05 \\
\multirow{3}{*}{$\begin{array}{l}\text { Storm from June, 20 to } \\
\text { July, 10 }\end{array}$} & 2.9 & 6.7 & 70.05 & 3.30 & 0.064 & 0.640 & 5.16 \\
& 1.7 & 5.4 & 45.50 & 1.98 & 0.067 & 0.647 & 3.07 \\
& 1.0 & 4.6 & 33.02 & 1.23 & 0.075 & 0.661 & 1.86 \\
individual storms from & 1.3 & 5.0 & 39.01 & 1.56 & 0.071 & 0.655 & 2.38 \\
10 to 28, July & 1.7 & 5.5 & 47.21 & 2.00 & 0.069 & 0.649 & 3.08 \\
\hline
\end{tabular}


The calculation of wave breaking depth with the indicated parameters showed (Table 4) that the bar could be displaced to the depths of up to $7 \mathrm{~m}$ in the maximum phase and later - to displace in the landward direction to $3 \mathrm{~m}$ depth. Such an assumption should be confirmed by field data or model calculations as at the moment there is no clear idea of how quickly the submarine bar rebuilds to wave conditions and displaces to the corresponding depth.

After the passage of this storm and before the relief survey at the end of July, three more small storms were noted. The longest of them, July 13-16, was characterized by a wave height of $1 \mathrm{~m}$. If we assume the underwater bar displacement to $3 \mathrm{~m}$ depth after the storm passage in the period from June 20 to July 10, then, according to expression (8), the bar at this wave will shift in the landward direction a crest lowering $\left(H s / h_{c}=1 / 3.08=0.32\right)$. Subsequent waves (July 19-21 and July 27-28) have slightly higher $H s$ values but they are shorter in time, i.e they can have a smaller morphodynamic effect.

The morphodynamics of the coastal profile before the relief survey in early November can be considered in a similar way. The second study period (July - August) is characterized by a large number of strong storms. In particular, four storms were noted, in which $H s$ value exceeded $3 \mathrm{~m}$ (Fig. 6). It is difficult to make assumptions about the intensity with which the underwater bar was displaced towards the sea during the strongest waves without intermediate data on the bottom topography. The available data provide evaluation of the underwater bar morphodynamics during the storms preceding the survey work. In 2-7 November period, a medium-strength storm, which can be conditionally divided into three stages (Table 5), was observed. Here, just as when considering the storms of the second half of July, it can be assumed that the underwater bar was displaced to up to $3 \mathrm{~m}$ depths, followed by movement towards the coast under effect of waves of lesser force. This can be judged by the values of the wave breaking depth in the first two stages of this period - 3.24 and $3.04 \mathrm{~m}$ (Table 5). The subsequent waves of a lesser force could cause the bar to shift towards the coast, since the condition, according to expression (8), is fulfilled:

$$
H s / h_{c}=1,1 / 3,04=0,36 .
$$

Final bar position at the time of the survey on November 8 does not correspond to the breaking depth of the previous waves, which may be due to the short duration of this storm and the large difference between the significant heights of the waves during the first two stages and the third stage $(1.7$ and $1.1 \mathrm{~m}$, respectively).

T a b l e 5

Intermediate variables and results of calculating the wave breaking depths $\left(d_{\mathrm{cr}}\right)$ during the storm on November, 2-7 preceding soundings in course of stage 4 (see Table 1 and Fig. 6)

\begin{tabular}{c|c|c|c|c|c|c}
\hline$H s, \mathrm{~m}$ & $T m, \mathrm{c}$ & $L_{\infty}, \mathrm{m}$ & $H_{\mathrm{cr}}, \mathrm{m}$ & $\xi$ & $\gamma_{\mathrm{cr}}$ & $d_{\mathrm{cr}}$ \\
\hline 1.7 & 6.6 & 67.98 & 2.18 & 0.082 & 0.675 & 3.24 \\
\hline 1.7 & 5.2 & 42.20 & 1.95 & 0.065 & 0.642 & 3.04 \\
\hline 1.1 & 4.0 & 24.97 & 1.23 & 0.062 & 0.636 & 1.94 \\
\hline \multicolumn{6}{c}{ PHYSICAL OCEANOGRAPHY VOL. 27 ISS. 4 (2020) }
\end{tabular}



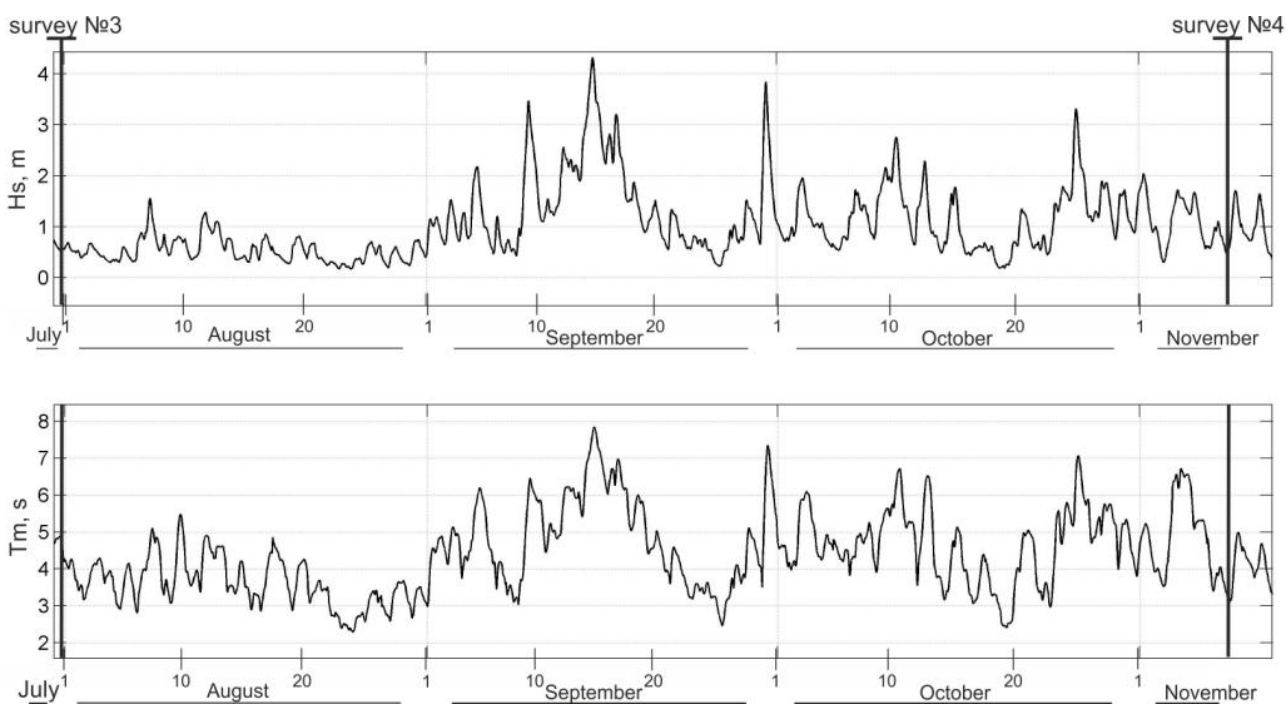

F i g. 6. Wave parameters (reanalysis ERA5) in July - August, 2019

\section{Conclusions}

1. The analysis of the underwater topography showed that for the period under study the external underwater bar can be characterized as uniform in depth with a two-dimensional character of morphodynamics, i.e. with a weak variability along the coast. According to comprehensive studies of the behavior of coastal systems with two underwater bars, the bar straightened along the coast is more susceptible to move towards the sea and degradation due to the increased countercurrent impact.

2. It was revealed that the underwater bar crest is located at depths close to the ones of wave breaking during the latest relatively strong and long-lasting wave.

3. The submarine bar displacement towards the coast in the period from May to July could have occurred under effect of a series of storm events, including an extreme storm ( $H s=4 \mathrm{~m}$ at the maximum development stage) with its gradual attenuation, as well as several storms of low strength $(H s \sim 1-1,5 \mathrm{~m})$. This conclusion was drawn on the basis of the assumption that the depth of the underwater bar crest corresponds to the breaking depth of the prevailing wave, and also proceeding from the literature data on the relationship between the wave height, the depth of the underwater bar crest and its morphodynamics.

4. The assessment of the parameters of storm waves and coastal profile morphodynamics made it possible to reveal that the underwater bar position does not always correspond to the breaking depth of the previous wave collapse. This may be related with the duration of the individual waves on the eve of the survey work and to the large difference between the wave parameters of the storms that followed one by one.

\section{REFERENCES}

1. Leontiev, I.O., 2011. Submarine Bars on Sandy Coasts. Oceanology, 51(1), pp. 141-147. https://doi.org/10.1134/S0001437011010115 
2. Leontiev, I.O., 2001. Coastal Dynamics: Waves, Currents, Sediment Transport. Moscow: GEOS, 272 p. (in Russian).

3. Price, T.D., Ruessink, B.G. and Castelle, B., 2014. Morphological Coupling in Multiple Sandbar Systems - a Review. Earth Surface Dynamics, 2(1), pp. 309-321. https://doi.org/10.5194/esurf-2-309-2014

4. Aleman, N., Robin, N., Certain, R., Barusseau, J.-P. and Gervais, M., 2013. Net Offshore Bar Migration Variability at a Regional Scale: Inter-Site Comparison (Languedoc-Roussillon, France). Journal of Coastal Research, 65(sp2), pp. 1715-1720. https://doi.org/10.2112/SI65290.1

5. Gervais, M., Balouin, Y. and Belon, R., 2012. Morfological Response and Coastal Dynamics Associated with Major Storm Events along the Gulf of Lions Coastline, France. Geomorphology, 143-144, pp. 69-80. https://doi.org/10.1016/j.geomorph.2011.07.035

6. Inman, D.L., Elwany, M.H.S. and Jenkins, S.A., 1993. Shorerise and Bar-Berm Profiles on Ocean Beaches. Journal of Geophysical Research: Oceans, 98(C10), pp. 18181-18199. https://doi.org/10.1029/93JC00996

7. Bernabeu, A.M., Medina, R. and Vidal, C., 2003. A Morphological Model of the Beach Profile Integrating Wave and Tidal Influences. Marine Geology, 197(1-4), pp. 95-116. https://doi.org/10.1016/S0025-3227(03)00087-2

8. Yates, M.L., Guza, R.T., O'Reilly, W.C. and Seymour, R.J., 2009. Overview of Seasonal Sand Level Changes on Southern California Beaches. Shore \& Beach, 77(1), pp. 39-46. Available at: https://pdfs.semanticscholar.org/817c/a0971803876b2723cc81fd03a4eb06495312.pdf [Accessed: 09 July 2020].

9. Group, T.W., 1988. The WAM Model - A Third Generation Ocean Wave Prediction Model. Journal of Physical Oceanography, 18(12), pp. 1775-1810. https://doi.org/10.1175/15200485(1988)018<1775:TWMTGO >2.0.CO;2

10. Rivas, M.B. and Stoffelen, A., 2019. Characterizing ERA-Interim and ERA5 Surface Wind Biases Using ASCAT. Ocean Science, 15(3), pp. 831-852. https://doi.org/10.5194/os-15-831-2019

11. Bruno, M.F., Molfetta, M.G., Totaro, V. and Mossa, M., 2020. Performance Assessment of ERA5 Wave Data in a Swell Dominated Region. Journal of Marine Science and Engineering, 8(3), 214. http://dx.doi.org/10.3390/jmse8030214

12. Shepard, F.P., 1950. Longshore-Bars and Longshore-Troughs. Technical memorandum No. 15. U.S. Beach Erosion Board, 32 p. Available at: https://babel.hathitrust.org/cgi/pt?id=mdp.39015095245075\&view=1up\&seq=1 [Accessed: 10 July 2020].

13. Larson, M. and Kraus, N.C., 1989. SBEACH: Numerical Model for Simulating StormInduced Beach Change. Technical Report CERC-89-9. US Army Engineering Waterways Experimental Station, $267 \mathrm{p}$.

14. Houser, C. and Greenwood, B., 2005. Profile Response of a Lacustrine Multiple Barred Nearshore to a Sequence of Storm Events. Geomorphology, 69(1-4), pp. 118-137. doi:10.1016/j.geomorph.2004.12.005

15. Leontiev I.O., 2014. [Morphodynamic Processes in the Coastal Zone of the Sea]. Saarbrücken: Lap Lambert Academic Publishing, 251 p. (in Russian).

About the authors:

Dmitry V. Korzinin - Senior Research Associate, V.P. Zenkovich laboratory of the sea shelf and coasts, Shirshov Institute of Oceanology of RAS (36 Nakhimovsky Prospekt, Moscow, 117997, Russian Federation), Ph. D. (Geogr.), Scopus Author ID: 56829564800, ORCID ID: 0000-0002-7365-8386, korzinin2000@mail.ru

Margarita N. Shtremel - Junior Research Associate, V.P. Zenkovich laboratory of the sea shelf and coasts, Shirshov Institute of Oceanology of RAS (36 Nakhimovsky Prospekt, Moscow, 117997, Russian Federation), Scopus Author ID: 55844240900, ORCID ID: 0000-0003-0045-0282, mnshtremel@gmail.com 
Contribution of the co-authors:

Dmitry V. Korzinin - collection of field data, development of main concept of the paper, writing the main sections of the paper and preparation of illustrations

Margarita N. Shtremel - collection of field data, primary processing of field data, writing a section about the application of wave reanalysis ERA5 data

All the authors have read and approved the final manuscript.

The authors declare that they have no conflict of interest. 